\title{
AFFORDANCE-BASED VIEW OF THE EFFECTS OF SELF-SERVICE TECHNOLOGY INTERACTIONS ON POST- PURCHASE BEHAVIORAL INTENTION
}

\author{
DOI: 10.17261/Pressacademia.2020.1193 \\ JMML- V.7-ISS.1-2020(1)-p.1-17
}

Ching-Hua Chou ${ }^{1}$, Yuan-Shuh Lii ${ }^{2}$,

${ }^{1}$ Feng Chia University, Ph.D. Program of Business, College of Business, 40724, Taichung, Taiwan.

joechou.f26@gmail.com, ORCID: 0000-0002-1656-9467

${ }^{2}$ Feng Chia University, Department of Marketing, College of Business, Feng Chia University, 40724, Taichung, Taiwan. yslii@fcuoa.fcu.edu.tw, ORCID: 0000-0002-3709-6160

Date Received: January 10, 2020

Date Accepted: March 22, 2020

To cite this document

Chou, C.H., Lii, Y.S., (2020). Affordance-based view of the effects of self-service technology interactions on post-purchase behavioral intention. Journal of Management, Marketing and Logistics (JMML), V.7(1), p.1-17.

Permemant link to this document: http://doi.org/10.17261/Pressacademia.2020.1193

Copyright: Published by PressAcademia and limited licenced re-use rights only.

\begin{abstract}
Purpose- The purpose of this study is to explore the influence of SST interaction experiences on service quality, consumer satisfaction, and the subsequent behavioral intentions of electronic word-of-mouth and repurchase.

Methodology- The research design adopts the convenience sampling method to survey consumers of an SST hotel located in central Taiwan, utilizing an on-site questionnaire upon checkout.

Findings- Findings indicate that interaction experiences, such as functional affordance and cognitive affordance, have a positive effect on SST's service quality and satisfaction. Customers with an excellent evaluation of SST service quality are more likely to be satisfied with SST and more willing to recommend or choose the same service in the future. Results also suggest that perceived self-control has a moderating effect on the relationship between cognitive affordance and SST service quality and satisfaction with SST.

Conclusion- This study develops a new model of the self-service technology (SST) interaction experience. This new model fills a research gap by providing an empirical study of the repeated use and commitment phases of the SST adoption model grounded in innovation diffusion theory.
\end{abstract}

Keywords: Self-service technology (SST), interaction experience, service quality, electronic word-of-mouth (eWOM), repurchase intention. JEL Codes: M31, D91, Q55

\section{INTRODUCTION}

On January 22, 2018, "Amazon Go" officially launched in Seattle, the United States. This innovative service uses in-store cameras, sensors, and deep learning algorithms to automatically identify items that consumers are removing from the store. Consumers do not need to scan the barcode through the checkout counter; instead, the system automatically charges them accordingly when they walk out of the storefront. This marks the first time in history that a company has tried to integrate mobile devices, cloud computing, computer vision, sensor fusion, deep learning algorithms, and other technologies to achieve the "Just Walk Out" shopping experience (Polacco and Backes, 2018). The store's launch represents a new milestone in the self-service technology (SST) experience.

Providing services through SST facilitates transactions in which buyers and sellers do not need direct contact (Meuter, Ostrom, Roundtree, and Bitner, 2000). This approach makes it more efficient both for employees to provide services and for customers to receive services, thus reducing labor costs (Globerson and Maggard, 1991) and improving business productivity (Bitner, Zeithaml, and Gremler, 2010). Introducing SST may benefit the service industry, however, lack of interpersonal interaction may even lead to decreased customer loyalty (Kim and Qu, 2014). A terrible initial interaction may lead an adopter to feel unwilling to use SST again 
(Wang, Harris, and Patterson, 2012). Enterprises experience harm when these related negative experiences spread widely through word of mouth. These issues are crucial to both management and theoretical development. Therefore, further exploration of this topic is necessary.

Based on Roger's (2003) innovation diffusion theory, Bitner, Ostrom, and Meuter (2002) developed a model of SST adoption, which divides the adoption process into six phases: awareness, investigation, evaluation, trial, repeated use, and commitment. Most studies on SST have focused on the evaluation and trial phases (Wang, Harris, and Patterson, 2013), examining the intention to adopt SST, decisions about whether to use it (Blut, Wang, and Schoefer, 2016; Meuter, Bitner, Ostrom, Brown, 2005), and how consumers' attitudes toward SST affect their adoption intention (Wang et al., 2012). By contrast, fewer studies have focused on the stage of repeated use and commitment. In other words, previous SST literature has focused less on the subjective experience of consumers after actually using SST (Wei, Torres, and Hua, 2017), the perceived service quality after using SST (Kallweit, Spreer, and Toporowski, 2014; Lee), and the satisfaction with SST after using it (Djelassi, Diallo, and Zielke, 2018). Still fewer studies have explored how SST evaluation affects subsequent consumer's behavioral intention through means such as word-of-mouth communication (Robertson, McDonald, Leckie, and McQuilken, 2016) and repurchase intention (Eriksson and Nilsson, 2007; Robertson et al., 2016), even though these topics are essential issues (Beatson, Lee, and Coote, 2007). Therefore, this study proposes a conceptual model to explore SST interaction experiences in the post-usage phase, the effect of these experiences on SST service quality and satisfaction, and the relationship between these influences and consumers' subsequent behavioral intentions, including word-of-mouth recommendation and repurchase intention.

\section{LITERATURE REVIEW}

\subsection{Evaluation of Self-Service Technology (SST)}

Meuter et al. (2000) defined SST as "technological interfaces that enable customers to produce a service independent of direct service employee involvement." The introduction of SST is a common way to achieve superior customer service across industries (Eriksson and Nilsson, 2007), and more and more companies are using SST to deliver innovative services (Kim, Christodoulidou, and Brewer, 2012), especially in service-oriented industries where both efficiency and service quality are essential, such as retail, catering, and tourism (Oh, Jeong, and Baloglu, 2013). As technology progresses, SST continues to evolve and play an increasingly critical role in providing services (Beatson et al., 2007).

Parasuraman, Zeithaml, and Berry (1985) explored the quality of service based on customer's expectations and experiences and argued that service quality depends on the difference between the customer's expected performance and assessment of the service. When SST replaces employees, part of the service quality depends on the interaction between consumers and the SST. Because SST requires consumers to participate in the service process, they are concerned with not only the outcome of service quality but also the process of service quality (Globerson and Maggard, 1991). Regardless of the process or outcome, the smaller the gap between the consumer's expectations of SST and the perceived outcome after their use, the better the perceived service quality. Therefore, this study defines SST service quality as the overall evaluation of effectiveness based on the difference between the consumer's expectation and the actual experience of SST.

In an SST setting, Lee (2008) argued that satisfaction is the extent to which consumers feel positive after using SST. Djelassi et al. (2018) observed that satisfaction with SST arises from the consumers' overall appraisement of the entire process of using SST, including the sum of positive feelings that consumers perceived before using SST, while using SST, and following the outcome provided by SST. Therefore, customer satisfaction with SST can be regarded as the extent of consumers' subjective positive feelings resulting from comparisons of their expectations before using SST, their experiences using SST, and the final result provided by SST.

If the consumer's overall evaluation of SST's service quality is excellent, they believe that their actual experience of SST is in line with pre-use expectations or even that the performance of SST is unexpectedly good. Based on expectation-confirmation theory, customers feel satisfied when the provided service meets or exceeds their expectations (Oliver, 1980). Therefore, this study proposes propose the following hypothesis:

\section{H1: SST service quality has positive effect on satisfaction with SST.}

\subsection{SST Interaction Experiences and SST Evaluation}

Based on previous research (Vakulenko, Hellström, and Oghazi, 2018), this study applies the theory of affordance to explore the utilitarian value of SST interaction experiences and its influence on SST evaluation from the perspective of human-machine 
interaction (HMI). The theory of affordance was introduced by psychologist Gibson (1979), who believed that affordance is a type of dynamic relationship that exists between animals and the natural environment. Norman (1988) extended the concept of affordance to the HMI design field. He argued that the affordance of an object is a dynamic relationship between the object and the user, which depends on the design features of the object and the user's ability and intention to manipulate the object. McGrenere and Ho (2000) pointed out that the user's intention and ability determine the user's relationship with the design attributes of the object. The affordance of an object only exists if users intend to use and are capable of operating the object. Consequently, the affordance of the same object may vary among different users.

\section{Functional Affordance}

Grgecic, Holten, and Rosenkranz (2015) defined functional affordance as the link between artifacts and operators under specific situations. Hartson (2003) argued that the purpose of functional affordance is to provide the necessary design to assist the user in accomplishing a task. McGrenere and Ho (2000) explored the relationship between affordance and usefulness and suggested that the usefulness of a design depends on what affordance it can offer operators in accomplishing their tasks. Past studies have defined usefulness as the ability of users to perform accurate and reliable tasks with the system (Yen, 2005) or the extent to which the system can assist users can achieve their mission (Ho and Ko, 2008). Therefore, in an SST setting, functional affordance can be regarded as a dynamic link relationship among SST design features, the consumer's ability, and their intention to use the technology, which can help users to complete their task accurately and reliably.

Past study have demonstrated out that service reliability is a critical factor of service quality (Parasuraman et al., 1988). When providing services through SST, reliability becomes an essential aspect of service quality (Orel and Kara, 2014; Shahid Iqbal, UI Hassan, and Habibah, 2018). Therefore, we propose the following hypothesis, consistent with the study by Grgecic et al. (2015).

H2a: Functional affordance has a positive effect on SST service quality.

Past studies have also exhibited positive relationships among reliability, usefulness, and satisfaction (Barua, Aimin, and Hongyi, 2018; Narteh, 2015; Robertson et al., 2016); therefore, we propose the following hypothesis:

H2b: Functional affordance has a positive effect on satisfaction with SST.

\section{Cognitive Affordance}

Hartson (2003) defined cognitive affordance as a design feature that facilitates or helps operators understand a process. Excellent cognitive affordance assists users in understanding the operation through clear and perceptible guidance. When the design of the system's affordance is apparent to the user and its function meets the original design goal, the system will be easy to use (Gaver, 1991). Therefore, cognitive affordance can be regarded as a type of dynamic relationship among system accessibility, consumer ability, and intention to use, which can help users to complete their tasks without effort.

Hartson (2003) argued that for the new and infrequent users, the focus of cognitive affordance is to provide ease of learning for unfamiliar users, which means that the cognitive affordance determines a design's ease of use, which is the extent to which users believe they can use a specific system without effort (Davis et al., 1989). Moreover, past studies have indicated that in the context of replacing personnel with technology, the ease-of-use of technology is an essential factor determining service quality (Dabholkar, 1996; Lee et al., 2013; Lin and Hsieh, 2011). Thus, cognitive affordance determines the ease of use of SST design, an essential factor of service quality. Therefore, the study proposes the following hypothesis:

H3a: Cognitive affordance has a positive effect on SST service quality.

Past studies have also identified a positive relationship between ease-of-use and satisfaction (Kim and Qu, 2014; Gunawardana and Perera, 2015); therefore, we propose the following hypothesis:

H3b: Cognitive affordance has a positive effect on satisfaction with SST.

\subsection{SST Evaluation and Behavior Intention}

Customer evaluation greatly affects subsequent customer behavior intentions, which in turn have a considerable influence on the company's operations. Zeithaml, Berry, and Parasuraman (1996) argued that positive behavioral intentions, including recommending services to others, saying positive things, and loyalty to the enterprise can be measured by dimensions such as word-of-mouth and repurchase intentions. 


\section{Electronic word-of-mouth (eWOM)}

Word-of-mouth is considered a particularly valuable tool for promoting company products and services (Abubakar and Mavondo, 2014). Compared with the marketing information of enterprises, consumers often place more trust in each other's opinions (Ng, David, and Dagger, 2011). Particularly through the Internet, its influence is correspondingly more profound. This study defines eWOM as related messages regarding the use or characteristics of a product or service, communicated in an unofficial form over the Internet.

Parasuraman et al. (1988) suggested that customers' perceptions of service quality are positively related to their willingness to recommend companies. In the context of SST, Lin and Hsieh (2006) argued that consumers' perceptions of SST service quality positively affect SST's favorable evaluation and word-of-mouth recommendations. Therefore, this study proposes the following hypothesis.

H4a: SST service quality positively affects eWOM.

Past studies have confirmed that satisfaction will positively influence the willingness of customers to recommend products or services (Xu, Peak, and Prybutok, 2015). In an SST setting, Lin and Hsieh (2007) argued that consumer satisfaction with SST will have a positive influence on favorable SST evaluations and will increase the likelihood that the consumer will recommend SST to other consumers. Liu's (2012) study indicated that SST satisfaction is positively correlated with behavioral intentions, including the willingness to recommend to others. Therefore, this study proposes the following hypothesis.

H5a: SST satisfaction positively affects eWOM

\section{Repurchase Intention}

Repurchase intention can be regarded as the individual's willingness to purchase the product or continue to use the service from the same company in the future (Chen and Chen, 2017). In an SST setting, Lin and Hsieh (2006) argued that consumers' perceived SST service quality is positively related to repeat purchase intention, and Lee (2015) suggested that SST service quality is a strong predictor of future use of SST. Other SST-related studies (Shamdasani, Mukherjee, and Malhotra, 2008, Kallweit et al., 2014) have illustrated that SST service quality perception is positively related to the willingness to reuse. Therefore, this study proposes the following hypothesis:

H4b: SST service quality positively affects repurchase intention.

In an SST setting, Lin and Hsieh (2006) argued that consumers who are satisfied with SST will be more willing to purchase repeatedly. Liu (2012) suggested that satisfaction with SST positively correlates with behavioral intentions of continuing to use SST devices in the future. Other studies (Wang et al., 2013; Robertson et al., 2016) have also confirmed that satisfaction with SST is positively related to willingness to reuse. Therefore, this study proposes the following hypothesis:

H5b: SST satisfaction positively affects repurchase intention.

\subsection{Moderating Effects of Perceived Self-Control}

Ajzen (1991) defined perceived control as the total amount that consumers think they can control their work or behavior. From a self-service perspective, perceived control over SST refers to the customer's perception of the ability to adapt and direct SST to fulfill service needs (Zhu, Nakata, Sivakumar, and Grewal, 2013). Perceived control depends on individual's belief in their control of the process and outcome of SST or the extent to which they dominate the interaction with SST (Collier and Sherrell, 2010). Therefore, in the context of SST, perceived self-control of SST refers to the total amount of control consumers perceive themselves to possess during a service encounter to dominate the interaction with SST and receive the expected result.

During the interaction with SST, customers have different ability to adapt and direct SST to fulfill their needs. Thus, the consumer's level of confidence in using SST may vary substantially (Zhu et al., 2013). Different levels of confidence will strengthen or weaken the affordance of SST, which in turn will affect the evaluation of SST service quality and satisfaction with SST. Dabholkar's (1996) study illustrated that consumers' perceived control affects their evaluation of self-service quality. Shamdasani et al. (2008) reported that perceived control exhibited the most significant impact on perceived service quality among all of the antecedents in their study. When consumers believe they have more control over the use of SST, they will be more satisfied with the quality of service. Therefore, this study proposes the following hypotheses: 
H6a: Perceived self-control moderates the effect of functional affordance on SST service quality.

H7a: Perceived self-control moderates the effect of cognitive affordance on SST service quality.

Barua et al. (2018) observed that users' perceptions of their control of SST affects the perceived reliability of SST, which in turn affects customer satisfaction. Yen and Gwinner (2003) argued that when consumers think they can control SST, their relationship with service providers will be more confident, and in turn, their satisfaction with SST will improve. Therefore, this study proposes the following hypotheses:

H6b: Perceived self-control moderates the effect of functional affordance on satisfaction with SST.

H7b: Perceived self-control moderates the effect of cognitive affordance on satisfaction with SST.

\section{DATA AND METHODOLOGY}

\subsection{Conceptual Model}

Based on the S-O-R model, the integrated theory of affordance (Gibson, 1979), the PZB service gap model (Parasuraman et al., 1985), and expectation-confirmation theory (Oliver, 1980), this study develops a conceptual model to explore the influence of SST interaction experiences on SST evaluation and subsequent consumer behaviors. The model argues that SST interaction experiences affect consumers' evaluation of SST service quality and satisfaction with SST. The assessment of SST in turn affects the subsequent behavioral intentions of consumers. The conceptual model is shown in Figure1.

Figure 1: Conceptual Model of the Impact of SST Interaction Experiences on SST Evaluation and Subsequent Consumer Behaviors

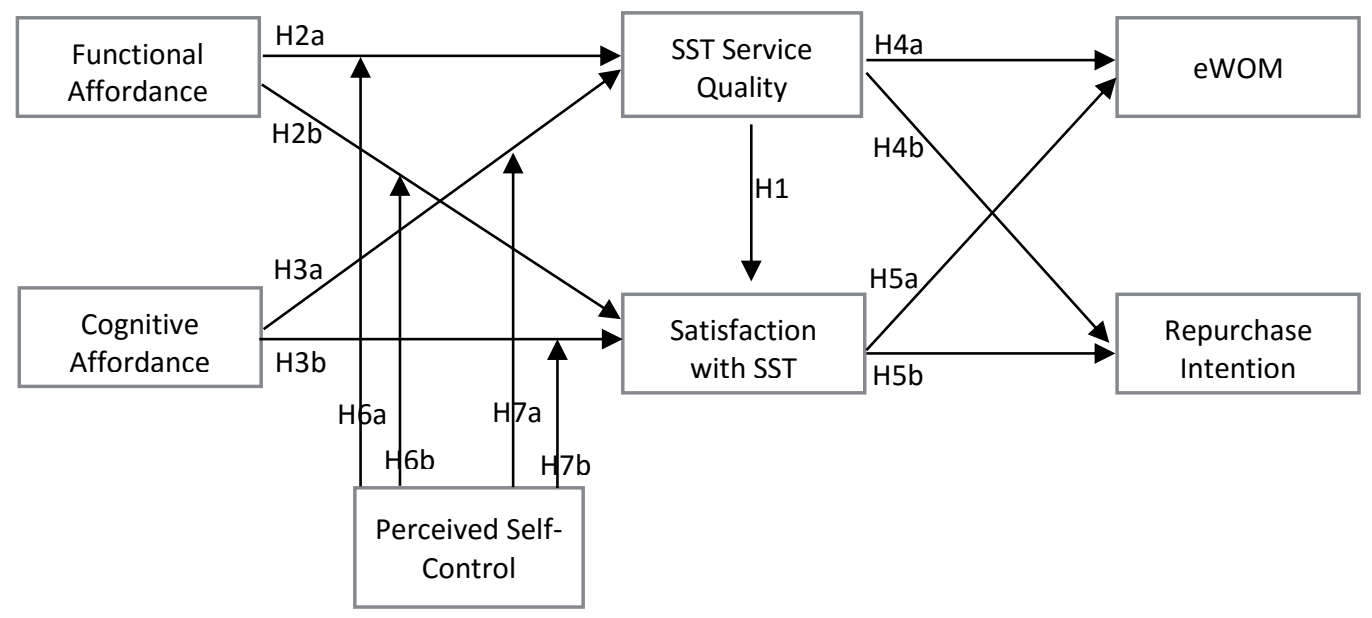

\subsection{Sample and data collection}

The research used the convenient sampling method to conduct a questionnaire survey to the hotel guests who had used SST to obtain service. The research site was an automated hotel located in central Taiwan, which uses SST to provide services traditionally offered by personnel, such as self-check-in and check-out, luggage storage, and robotic food ordering. The hotel's guests checkin, check-out, store luggage by themselves through automated equipment and order food via robot.

Respondents were asked about their willingness to participate in the study when they completed the self-checkout by using SST before leaving the hotel. The data collection process was divided into two phases, namely the pretest and the formal investigation. First, twenty persons who had used SST were invited to complete questionnaires, which were then revised according to problems identified in the process. The final result of the pretest stage was to confirm the appropriateness of the questionnaire design. Second, the formal investigation was conducted after the pre-test phase, collecting more than 300 samples throughout four weeks. The questionnaire was based on a 5-point Likert scale, with responses ranging from $1=$ strongly disagree to $5=$ strongly agree, where the higher the score, the greater the extent of the subject's agreement with the measurement item. 


\subsection{Measurement}

This study uses multiple measurement scales to measure each variable. All scales are constructed from previous studies and modified and adapted to the context of this study. The measurement items suitable for use in SST operations were selected, modified, and translated to Chinese as appropriate for the context of the study. The measurement items and references are shown in appendix 1 (Table 1).

\section{Reliability and validity}

Table 2 provides the means and standard deviations of the variables, together with the correlation between the scale reliability and each construct. The scale reliability adopts the internal consistency method to estimate the internal consistency of the scale by obtaining Cronbach's alpha values, which range from 0.80 (SST quality of service) to 0.96 (repurchase intention), thus exceeding the recommended value of 0.7 (Nunnally, 1967).

According to Fornell and Larcker (1981), this study uses compositional reliability (CR) to examine the internal consistency of multiitem scales in the model. The results of the analysis are shown in measurement model and factor loading in appendix 2 (Table 3 ). The CR of each construct ranges from 0.79 (SST service quality) to 0.96 (repurchase intention), thus exceeding the recommended minimum of 0.70 (Bagozzi, 1980). The results indicate that all multi-item scales in the measurement model possess adequate internal consistency for further analysis of the structural model.

Table 2: Mean, standard deviation and correlation of variables

\begin{tabular}{|c|c|c|c|c|c|c|c|c|c|}
\hline Variable & Mean & SD & VAVE & FA & $\mathrm{CA}$ & SSTSQ & SSTSAT & eWOM & $\mathrm{RI}$ \\
\hline FA & Mar.93 & 0.70 & 0.81 & $(0.85)$ & & & & & \\
\hline$C A$ & Mar.82 & 0.67 & 0.79 & $0.38^{* *}$ & $(0.83)$ & & & & \\
\hline SSTSQ & Mar.93 & 0.60 & 0.75 & $0.58^{* *}$ & $0.51^{* *}$ & $(0.80)$ & & & \\
\hline SSTSAT & 4. Haz & 0.52 & 0.82 & $0.66^{* *}$ & $0.53^{* *}$ & $0.67^{* *}$ & $(0.85)$ & & \\
\hline eWOM & 4.Ağu & 0.53 & 0.77 & $0.43^{* *}$ & $0.32^{* *}$ & $0.55^{* *}$ & $0.62 * *$ & $(0.83)$ & \\
\hline RI & 4. $\mathrm{Haz}$ & 0.61 & 0.95 & $0.45^{* *}$ & $0.42 * *$ & $0.59 * *$ & $0.66 * *$ & $0.88 * *$ & $(0.96)$ \\
\hline
\end{tabular}

Notes: ${ }^{*} p<.05 ;{ }^{* *} p<.01 ; \mathrm{N}=283$; Chronbach's alpha, reported in parentheses in the diagonal, SD: standard deviation, VAVE: square root of AVE, FA: Functional Affordance, CA: Cognitive Affordance, SSTSQ: SST Service Quality, SSTSAT: Satisfaction with SST, eWOM: Electronic Word-OfMouth, RI: Repurchase Intention.

This study applies convergent and discriminant validity to determine construct validity. The standardized factor loadings and the average variance extracted (AVE) are used to measure convergent validity. The analysis results are revealed in measurement model and factor Loading in appendix 2 (Table 3). All standardized factor loadings in the construct are above 0.68 and hence can be considered significant (Hair, Black, Babin, and Anderson, 2010). In addition, Table 3 shows the AVE estimation for all constructs, all values greater than 0.50 . To evaluate the discriminant validity, the square root of the AVE in each construct is compared with the correlation coefficient between the two constructs (Fornell and Larcker, 1981). The results suggest that constructs in the measurement model have an acceptable level of discriminant validity (see Table 2).

\section{Common Method Variance}

Because this study used self-reported measurement tools to collect samples, Harman's (1976) single factor test (Podsakoff, MacKenzie, Lee, and Podsakoff, 2003) is applied to examine the common method variance (CMV) problem (Avolio, Yammarino, and Bass, 1991). The result of factor analysis indicates that there are five factors with eigenvalues greater than 1 . The variance explained of the first factor is $46.995 \%$, and the total variance explained is $72.999 \%$. According to verification results, no single factor explains most of the variability, and variance explained by any single factor does not exceed the commonly accepted threshold of 50\%. Thus, the CMV problem was not serious.

\section{DATA ANALYSIS AND RESULTS}

\section{Structural Model Effects}

This study uses structural equation modeling (SEM) to test the proposed model and hypotheses. The overall model indicates that 
the chi-square value $\chi 2$ is 520.39 , and the degree of freedom is 124 . Because the chi-square value is affected by the number of samples, this result is significant $(p<.001)$, and the value of the observed chi-square value/degree of freedom $(\chi 2 / d f=4.197)$ is still within acceptable limits (Wheaton et al., 1977). Other fitness indexes are also used, including GFI (0.83), PGFI (0.77), TLI (0.88), CFI (0.90), PNFI (0.71), and RMSEA (0.11), and their values fall within acceptable limits (Bagozzi, 1980).

According to SEM analysis results shown in Figure 2 and Table 4, the standardized estimation of the model indicates that the SST service quality has a significant positive influence on SST satisfaction, thus supporting $\mathrm{H} 1$. In other words, the higher the quality of service perceived by customers using SST, the more satisfied they are with SST. This finding is consistent with previous research (Lee, 2008). As predicted, functional affordance exhibits a positive relationship with SST service quality $(B=.593, p<.001)$ and satisfaction with SST $(B=.407, p<.001)$, thus supporting Hypotheses 2 ( $\mathrm{H} 2 \mathrm{a}$ and $\mathrm{H} 2 \mathrm{~b}$ ). Cognitive affordance exhibits a positive relationship with SST service quality $(B=.322, p<.001)$ and satisfaction with SST $(B=.163, p<.01)$, thus supporting Hypotheses 3 ( $\mathrm{H3a}$ and $\mathrm{H3b}$ ). Additionally, SST service quality positively affects eWOM $(B=.032, p<.05)$ and repurchase intention $(B=.292$, $p<.05$ ), and its path coefficient is statistically significant, thus supporting Hypotheses 4 ( $\mathrm{H} 4 \mathrm{a}$ and H4b). Customer's satisfaction with SST positively affects eWOM $(B=.471, p<.001)$ and repurchase intention $(B=.465, p<.001)$, and its path coefficient is also statistically significant, thus supporting Hypotheses 5 ( $\mathrm{H} 5 \mathrm{a}$ and $\mathrm{H} 5 \mathrm{~b}$ ).

\section{Figure 2: Structural Equation Modeling (SEM)}

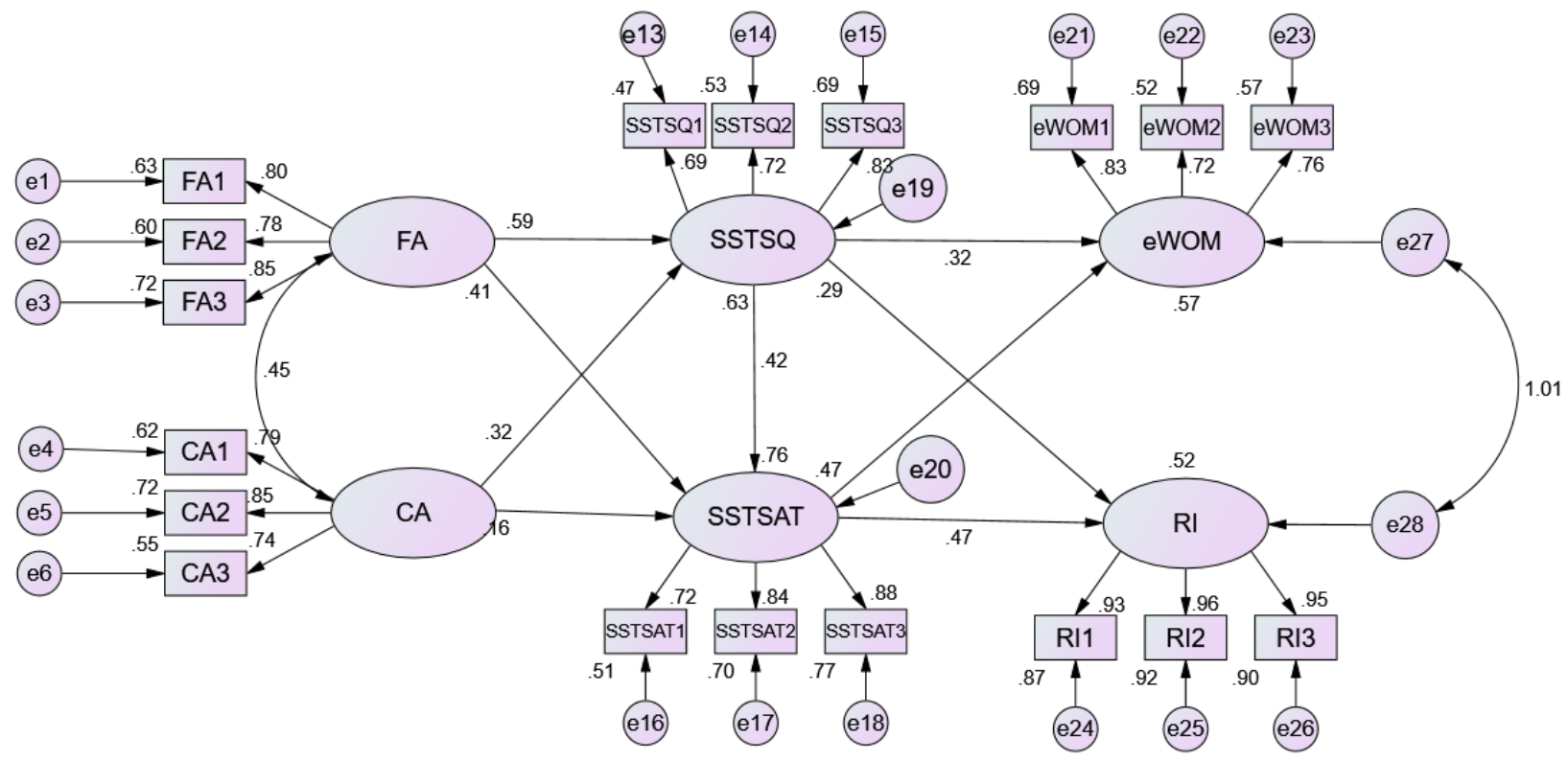

Notes: FA: Functional Affordance, CA: Cognitive Affordance, SSTSQ: SST Service Quality, SSTSAT: Satisfaction with SST, eWOM: Electronic Word-Of-Mouth, RI: Repurchase Intention 
Table 4: Results of Structural Equation Modeling (SEM) Analysis

\begin{tabular}{lll}
\hline Hypotheses & SR & CR \\
\hline H1 $\quad$ SST service quality $\rightarrow$ Satisfaction with SST & 0.422 & $4.308^{* * *}$ \\
H2a Functional affordance $\rightarrow$ SST service quality & 0.593 & $7.703^{* * *}$ \\
H3a Cognitive affordance $\rightarrow$ SST service quality & 0.322 & $4.807^{* * *}$ \\
H2b Functional affordance $\rightarrow$ Satisfaction with SST & 0.407 & $4.907^{* * *}$ \\
H3b Cognitive affordance $\rightarrow$ Satisfaction with SST & 0.163 & $2.700^{* *}$ \\
H4a SST service quality $\rightarrow$ eWOM & 0.32 & $2.549 *$ \\
H4b SST service quality $\rightarrow$ Repurchase intention & 0.292 & $2.588^{*}$ \\
H5a Satisfaction with SST $\rightarrow$ eWOM & 0.471 & $3.782^{* * *}$ \\
H5b Satisfaction with SST $\rightarrow$ Repurchase intention & 0.465 & $4.145^{* * *}$ \\
\hline
\end{tabular}

Notes: ${ }^{*} p<.05,{ }^{* *} p<.01 ;{ }^{* * *} p<.001 ;$ SR: Standardized Regression; CR: Critical Ratio.

\section{Moderating Effects}

In addition to testing the direct effects with SEM following Jones and Reynolds (2006), this study uses hierarchical regression analysis (Aiken and West, 1991) to test the hypothesized moderating effect. First, this study tests the moderating effects of perceived self-control on the relationship between functional affordance and SST service quality (H6a) and on the relationship between functional affordance and satisfaction with SST (H6b). Table 5 displays the results of the data analysis. We estimate an initial regression equation (Model 1), including SST service quality and satisfaction with SST as dependent variables respectively, and utilizing functional affordance and perceived self-control as independent variables. In Model 2, the hypothesized interactions are added. Results reveal that the functional affordance $x$ perceived self-control interaction is not statistically significant for SST service quality $(B=-0.032, t=-0.694, p>.05)$ and SST satisfaction $(\theta=0.011, t=0.276, p>.05)$. Thus, Hypotheses 6 (H6a and $\mathrm{H6b}$ ) are not supported.

Table 5: Hierarchical Regression Analysis of Hypotheses 6

\begin{tabular}{|c|c|c|c|c|}
\hline & \multicolumn{2}{|l|}{ Model 1} & \multicolumn{2}{|l|}{ Model 2} \\
\hline & $\beta$ & $t$-value & $\boldsymbol{\beta}$ & $t$-value \\
\hline \multicolumn{5}{|c|}{ Dependence variable: SST Service Quality (SSTSQ) } \\
\hline \multicolumn{5}{|l|}{ Independent variables: } \\
\hline Functional Affordance (FA) & 0.407 & $7.929 * * *$ & 0.414 & $7.888 * * *$ \\
\hline Perceived Self-Control (PSC) & 0.359 & $7.004 * * *$ & 0.359 & $7.002 * * *$ \\
\hline Interactions: FA x PSC & - & - & -0.032 & -0.694 \\
\hline$R^{2}$ & 0.436 & & 0.437 & \\
\hline$F$ value & 108.121 & & 72.108 & \\
\hline \multicolumn{5}{|c|}{ Dependence variable: Satisfaction with SST (SSTSAT) } \\
\hline \multicolumn{5}{|l|}{ Independent variables: } \\
\hline Functional Affordance (FA) & 0.475 & $10.335^{* * *}$ & 0.472 & $10.023^{* * *}$ \\
\hline Perceived Self-Control (PSC) & 0.382 & $8.307^{* * *}$ & 0.382 & $8.291 * * *$ \\
\hline Interactions: FA x PSC & - & - & 0.011 & 0.276 \\
\hline $\mathrm{R}^{2}$ & 0.547 & & 0.547 & \\
\hline$F$ value & 168.977 & & 112.305 & \\
\hline
\end{tabular}

Notes: ${ }^{*} p<.05,{ }^{* *} p<.01 ; * * p<.001$

Similarly, this study tests the moderating effects of perceived self-control on the relationship between cognitive affordance and SST service quality (H7a) and on the relationship between cognitive affordance and satisfaction with SST (H7b). Table 6 shows the 
results of data analysis. We estimate an initial regression equation (Model 1), including SST service quality and satisfaction with SST as dependent variables, respectively, utilizing cognitive affordance and perceived self-control as independent variables. In Model 2, the hypothesized interactions are added. The results reveal that the cognitive affordance $\times$ perceived self-control interaction was statistically significant for SST service quality $(B=0.120, t=2.507, p<.05)$ and satisfaction with SST $(B=0.135, t=$ $2.988, p<.01$ ), thus supporting Hypotheses 7 (H7a and H7b).

Table 6: Hierarchical Regression Analysis of Hypotheses 7

\begin{tabular}{lllll}
\hline & Model 1 & \multicolumn{2}{c}{ Model 2 } \\
& $\boldsymbol{\beta}$ & t-value & $\boldsymbol{\beta}$ & $\boldsymbol{t}$-value \\
\hline $\begin{array}{l}\text { Dependence variable: SST Service Quality (SSTSQ) } \\
\text { Independent variables: }\end{array}$ & & & & \\
$\quad$ Cognitive Affordance (CA) & 0.324 & $6.227^{* * *}$ & 0.321 & $6.208^{* * *}$ \\
$\quad$ Perceived Self-Control (PSC) & 0.41 & $7.877^{* * *}$ & 0.381 & $7.179^{* * *}$ \\
$\quad$ Interactions: CA x PSC & - & - & 0.12 & $2.507^{*}$ \\
$\mathrm{R}^{2}$ & 0.393 & & 0.406 & \\
F value & 90.68 & & 63.689 & \\
Dependence variable: Satisfaction with SST (SSTSAT) & & & & \\
Independent variables: & & & & \\
$\quad$ Cognition Affordance (CA) & 0.317 & $6.427^{* * *}$ & 0.313 & $6.426^{* * *}$ \\
Perceived Self-Control (PSC) & 0.469 & $9.498^{* * *}$ & 0.436 & $8.729^{* * *}$ \\
Interactions: CA x PSC & - & - & 0.135 & $2.988^{* *}$ \\
$\mathrm{R}^{2}$ & 0.455 & & 0.471 & \\
$F$ value & 116.646 & & 82.942 & \\
\hline
\end{tabular}

Notes: ${ }^{*} p<.05,{ }^{* *} p<.01 ; * * *<.001$

\section{DISCUSSION AND CONCLUSION}

\section{Conclusion and Findings}

The results of this study indicate that both functional affordance and cognitive affordance have a positive influence on SST service quality and satisfaction with SST. Overall, when the interaction experiences between customer and SST are more favorable, the evaluation of SST is more positive. This finding is consistent with previous research on the effect of the SST interaction experience on service quality (Grgecic et al., 2015) and customer satisfaction (Robertson et al., 2016). Compared with cognitive affordance, functional affordance has a greater influence on SST service quality and satisfaction with SST. One possible explanation is that ease of use is more important in members' initial SST adoption decision, rather than in the case of those who already use these SSTs (Robertson et al., 2016). Another possible reason is that most people (83.5\%) in this survey were encountering this type of service for the first time. According to Dabholkar (1996), customers may be especially worried about new technology-based forms of service because they may envision some performance risk in that these services may not work well or deliver the expected level of reliability. Therefore, customers are especially concerned about the functional affordance of SST. In addition, the reason may also be related to the type of SST. Usually, customers who use public SST need to ensure fast and successful use of SST because they do not want to feel embarrassed or they delay others (Gelbrich and Sattler, 2014).

Analysis of the structural model also indicates that SST service quality plays a crucial role in improving SST satisfaction and behavioral intentions. The higher the customers' evaluation of SST service quality, the higher their satisfaction with SST, which is consistent with previous findings (Lin and Hsieh, 2006; Shamdasani et al., 2008). They are also more willing to recommend the service to friends or others and to choose the service at a later opportunity. This result is consistent with the study by Orel and Kara (2014), who observed that the quality of service in the supermarket self-checkout system positively effects customer satisfaction and loyalty. The analysis results also show that consumers' satisfaction with SST is significantly positively correlated with word-of-mouth recommendation and repurchase intention. Consumers with high satisfaction with SST are more willing to spread positive messages and revisit the service. This finding is consistent with previous research (Lin and Hsieh, 2006; Robertson 
et al., 2016; Shahid Iqbal et al., 2018).

The results of the hierarchical regression analysis illustrate that perceived self-control has no moderating effect on the relationship between functional affordance and SST service quality and satisfaction with SST. However, perceived self-control has a moderating effect on the relationship between cognitive affordance and SST service quality and satisfaction with SST. The cognitive affordance of SST refers to the relationship among the accessibility of SST, the customers' use intent, and their ability. This relationship determines how easy it is for customers to complete the expected service and is positively related to SST's service quality and SST satisfaction. In an SST setting, the customer's capability becomes a critical factor in determining how easy to interact with SST. In general, heavy users of technology are more confident in the ability to use technology (Meuter et al., 2005). An individual's confidence in his or her ability to command technology to obtain the desired consequence is the perceived control over technology (Barua et al., 2018). Therefore, customers with rich experience in technology will have a higher degree of perceived control over technology, and they will find technology more straightforward to use than those with insufficient technology experience (Hackbarth, Grover, and Yi 2003). Although the design of SST's accessibility was the same for everyone in this study, experienced customers find it easier to access and require less effort to interact with SST. Therefore, customers with stronger perceived selfcontrol will strengthen the influence of the cognitive affordance on SST service quality and satisfaction with SST.

\section{Managerial Implications}

For enterprises implementing SST operation, it is crucial to understand how consumers evaluate the use of SST so that the company can improve service performance accordingly (Meuter et al., 2000). Based on these findings, this study makes several recommendations for SST system developers or companies planning to use SST to provide services.

First, although attracting consumers to start using SST is an essential first step, the final assessment of the success of introducing SST to provide services depends on whether consumers are willing to continue using it (Bhattacherjee, 2001). Enterprises can continue to generate profits only when consumers are willing to revisit the service or attract more customers to participate in consumption through word of mouth. Therefore, it is essential for companies to understand factors that influence existing customers' willingness to continue using SST (Robertson et al., 2016).

Second, the influence of factors evaluating SST at different phases in the SST adoption model may vary. Managers need to focus on different priorities in each stage. Implicit factors of SST interaction experience, such as enjoyment, can be successful in attracting consumers during the phase of evaluation and trial. However, if enterprises want to maintain long-term profitability, they must strengthen the explicit factors of the SST interaction experiences (such as functional and cognitive affordance) during the phase of repeated use and commitment.

Third, the interaction between SST and users is a dynamic link. The enterprise shall spend more efforts on this link when planning and designing SST implementation. The SST's design attributes can be designed to be dynamically adjusted under different situations. For example, the function menu may be dynamically presented to users during different business hours to improve ease of use and system performance.

Fourth, the scenarios of the rush hour may affect the user's evaluation of SST for the public SST. The interaction experiences of SST may be negatively affected under the pressure of the waiting line during rush hours, especially for those who are anxious about technology (Blut et al., 2016). The waiting pressure can be reduced by dispersing crowd through means such as adding SST machines, allowing the use of mobile phones to check out, or adding temporary personnel during rush hours to help customers to complete the check-out process more rapidly. The enterprise should invest resources in preventing the embarrassment of using public SST.

Fifth, Bitner et al. (2002) argued that the failure of technology and services is the main reason why customers stop using SST. In addition to focusing on the interaction experience of SST, enterprises must explore how to conduct service failure recovery in an SST interaction. Ha and Jang (2009) pointed out that enterprises can effectively solve the customer's loyalty problems caused by service failure if they can properly let customers feel distributive, procedural, and interactional justice after the service failure occurs. Among them, procedural justice had the strongest effect on service recovery satisfaction (Lii, Pant, and Lee, 2012). Therefore, enterprises should establish standard operating procedures quickly and properly solve the problem when a service failure occurs. Ensuring that customers feel that they have been treated fairly has a positive effect on subsequent positive wordof-mouth and repurchase intentions.

Finally, this study recommends that enterprises strengthen the customer's sense of control and provide more choices to enhance 
the customer's perceived self-control over SST. Regarding the sense of control, one approach is to strengthen the power of predictability, which represents the extent to which the unexpected aspects of SST are reduced. Improving customers' understanding and ability to predict the service process and consequences of using SST will cause them to perceive more controllability (Lee and Allaway, 2002). Perceived control increases when users are more able to control their choices and predict the consequences of events (Zhu, Nakata, Sivakumar, and Grewal, 2007). For example, the official website may provide an instructional video on using SST, or the company may provide a step-by-step demonstration video of SST operation on site. These countermeasures may help to improve predictability and controllability by reducing the degree of unexpected aspects of SST, thus enhancing the perception of control, thereby increasing the customer's perceived self-control over SST. Regarding the provision of more choices, Zhu et al. (2013) pointed out that customers with less perceived control may view the technology as imposing more constraints rather than allowing more choices, so increasing the available options can improve their perceived control. Therefore, the enterprise can consider offering customers more check-out options, such as check-out in their room or using the mobile phone to check-out directly. In addition to pre-paid on the Internet, the customer may be provided with more payment options, such as credit card and mobile payment on site. Allowing customers to decide freely how to obtain services by themselves will help enhance customer perceived control (Hui and Bateson, 1991). Moreover, enterprises may consider hiring temporary service personnel at rush business hours. This countermeasure not only enhances sense of control by providing to help customers evaluate, adapt SST but also provide more service options to customer. Thus, although temporary service personnel will increase labor costs, it is worthy of further consideration by managers as a trade-off between cost and performance.

\section{Limitations and Future Research Directions}

This study has certain limitations. While explaining these limitations, it also suggests future research directions. First, because the model of this study only surveyed participants in the environment of hotel operations, thus research results should be applied cautiously to other industries that use SST to provide services. Future research may consider additional support in the context of other service industries to increase the inference of the findings of this study.

Second, our sample consists mainly of travelers from Taiwan, China, and Hong Kong. Their responses may not be fully applicable to the entire population, especially regarding culturally relevant characteristics because cognitive, emotional, and behavioral responses may vary by culture (Cole, Bruschi, and Tamang, 2002). Enjoyment is considered to be more critical in individualistic cultures (Blut et al., 2016). Future research can explore the cognitive and behavioral responses of multinational consumers and further expand cross-cultural understanding of the use of SST.

Third, because of time and cost constraints, this study used cross-sectional data rather than longitudinal research. Future research may continuously collect longitudinal data through the company to understand the long-term influence of SST on corporate revenues and profits in a service environment without interpersonal interaction (Meuter et al., 2005). After collecting sufficient data, analysis can be further undertaken through the collaborative filtering method to predict potential consumers' preferences for the SST interaction experience as a reference for improving the system.

Finally, the research framework should be expanded to examine how SST interaction experiences affect brand-related outcomes such as brand identity, brand attitude, brand satisfaction, and brand loyalty.

\section{REFERENCES}

Abubakar Binta, and Mavondo Felix (2014). Tourism destinations: Antecedents to customer satisfaction and positive word-of-mouth. Journal of Hospitality Marketing and Management, 23(8), 833-864

Aiken Leona S., West Stephen G., and Reno Raymond R. (1991). Multiple regression: Testing and interpreting interactions. Thousand Oaks, CA: Sage.

Ajzen Icek (1991). The theory of planned behavior. Organizational Behavior and Human Decision Processes, 50(2), $179-211$.

Avolio Bruce J., Yammarino Francis J., and Bass Bernard M. (1991). Identifying common methods variance with data collected from a single source: An unresolved sticky issue. Journal of management, 17(3), 571-587.

Bagozzi Richard P. (1980). Performance and satisfaction in an industrial sales force: An examination of their antecedents and simultaneity. Journal of Marketing, 44(2), 65-77. 
Barua Zapan, Aimin Wang, and Hongyi Xu (2018). A perceived reliability-based customer satisfaction model in self-service technology. The Service Industries Journal, 38(7-8), 446-466.

Beatson Amanda, Lee Nick, and Coote Leonard V. (2007). Self-service technology and the service encounter. The Service Industries Journal, 27(1), 75-89.

Bhattacherjee Anol (2001). Understanding information systems continuance: an expectation-confirmation model. MIS quarterly, 25(3) 351-370.

Bitner Mary Jo, Ostrom Amy L., and Meuter Matthew L. (2002). Implementing successful self-service technologies. Academy of Management Perspectives, 16(4), 96-108.

Bitner Mary Jo, Zeithaml Valarie A., and Gremler Dwayne D. (2010). Technology's impact on the gaps model of service quality. In Handbook of service science (pp. 197-218). Boston, MA: Springer.

Blut Markus, Wang Cheng, and Schoefer Klaus (2016). Factors influencing the acceptance of self-service technologies: A meta-analysis. Journal of Service Research, 19(4), 396-416.

Brady Michael K., and Cronin Jr. Joseph J. (2001). Some new thoughts on conceptualizing perceived service quality: a hierarchical approach. Journal of Marketing, 65(3), 34-49.

Chen Chih-Cheng Volvic, and Chen Chih-Jou (2017). The role of customer participation for enhancing repurchase intention. Management Decision, 55(3), 547-562.

Cole Pamela M., Bruschi Carole J., and Tamang Babu L. (2002). Cultural differences in children's emotional reactions to difficult situations. Child Development, 73(3), 983-996.

Collier Joel E., and Sherrell Daniel L. (2010). Examining the influence of control and convenience in a self-service setting. Journal of the Academy of Marketing Science, 38(4), 490-509.

Cronin Jr Joseph J., Brady Michael K., and Hult, G. Tomas M. (2000). Assessing the effects of quality, value, and customer satisfaction on consumer behavioral intentions in service environments. Journal of Retailing, 76(2), 193-218.

Dabholkar, Pratibha A. (1996). Consumer evaluations of new technology-based self-service options: an investigation of alternative models of service quality. International Journal of Research in Marketing, 13(1), 29-51.

Davis Fred D. (1989). Perceived usefulness, perceived ease of use, and user acceptance of information technology. MIS Quarterly, 13(3) 319-340.

Davis Fred D., Bagozzi, Richard P., and Warshaw Paul R. (1989). User acceptance of computer technology: a comparison of two theoretical models. Management Science, 35(8), 982-1003

Djelassi Souad, Diallo Mbaye Fall, and Zielke Stephan (2018). How self-service technology experience evaluation affects waiting time and customer satisfaction? A moderated mediation model. Decision Support Systems, 111, 38-47.

Eriksson Kent, and Nilsson Daniel (2007). Determinants of the continued use of self-service technology: The case of Internet banking. Technovation, 27(4), 159-167.

Fornell Claes, and Larcker David F. (1981). Structural Equation Models With Unobservable Variables and Measurement Error: Algebra and Statistics. Journal of Marketing Research, 18, 39-50.

Gaver William W. (1991, April). Technology affordances. In Proceedings of the SIGCHI conference on Human factors in computing systems (pp. 7984). ACM.

Gelbrich Katja, and Sattler Britta (2014). Anxiety, crowding, and time pressure in public self-service technology acceptance. Journal of Services Marketing, 28(1), 82-94.

Gibson James J. (1979). The Ecological Approach to Visual Perception. Boston, MA: Houghton Mifflin.

Globerson Shlomo, and Maggard Michael J. (1991). A conceptual model of self-service. International Journal of Operations and Production Management, 11(4), 33-43.

Grgecic Daniel, Holten Roland, and Rosenkranz Christoph (2015). The impact of functional affordances and symbolic expressions on the formation of beliefs. Journal of the Association for Information Systems, 16(7), 580.

Gunawardana, H. M. R. S. S., and Perera, W. L. M. V. (2015). Impact of self service technology quality on customer satisfaction: A case of retail banks in western province in Sri Lanka. Gadjah Mada International Journal of Business, 17(1), 1. 
Ha Jooyeon, and Jang SooCheong Shawn (2009). Perceived justice in service recovery and behavioral intentions: The role of relationship quality. International Journal of Hospitality Management, 28(3), 319-327.

Hackbarth Gary, Grover Varun, and Mun Yi Y. (2003). Computer playfulness and anxiety: positive and negative mediators of the system experience effect on perceived ease of use. Information and Management, 40(3), 221-232.

Hair Joseph F., Black, B., Babin, B., and Anderson, R. E. (2010). Multivariate Data Analysis 7th Ed. Upper Saddle River, NJ: Pearson Prentice Hall. Harman Harry H. (1976). Modern factor analysis. Chicago, IL: University of Chicago press.

Harrison-Walker, L. Jean (2001). The measurement of word-of-mouth communication and an investigation of service quality and customer commitment as potential antecedents. Journal of Service Research, 4(1), 60-75.

Hartson Rex (2003). Cognitive, physical, sensory, and functional affordances in interaction design. Behaviour and Information Technology, 22(5), 315-338.

Ho Shu-Hsun and Ko Ying-Yin (2008). Effects of self-service technology on customer value and customer readiness: The case of Internet banking. Internet Research, 18(4), 427-446.

Hu Michael K., and Bateson John E. (1991). Perceived control and the effects of crowding and consumer choice on the service experience. Journal of Consumer Research, 18(2), 174-184.

Jeon Myunghee Mindy, and Jeong Miyoung (2017). Customers' perceived website service quality and its effects on e-loyalty. International Journal of Contemporary Hospitality Management, 29(1), 438-457.

Jones Michael A., and Reynolds Kristy E. (2006). The role of retailer interest on shopping behavior. Journal of Retailing, 82(2), 115-126.

Kallweit Katrin, Spreer Philipp, and Toporowski Waldemar (2014). Why do customers use self-service information technologies in retail? The mediating effect of perceived service quality. Journal of Retailing and Consumer Services, 21(3), 268-276.

Kim Jungsun, Christodoulidou Natasa, and Brewer Pearl (2012). Impact of individual differences and consumers' readiness on likelihood of using self-service technologies at hospitality settings. Journal of Hospitality and Tourism Research, 36(1), 85-114.

Kim Miyoung, and Qu Hailin (2014). Travelers' behavioral intention toward hotel self-service kiosks usage. International Journal of Contemporary Hospitality Management, 26(2), 225-245.

Lee Hyun-Joo (2008). Technology-based self-service kiosks in retailing: An optional channel for customer service (Doctoral dissertation). Knoxville, TN: University of Tennessee.

Lee Hyun-Joo (2015). Consumer-to-store employee and consumer-to-self-service technology (SST) interactions in a retail setting. International Journal of Retail and Distribution Management, 43(8), 676-692.

Lee Jungki, and Allaway Arthur (2002). Effects of personal control on adoption of self-service technology innovations. Journal of Services Marketing, 16(6), 553-572.

Liang Rong-Da, and Zhang Jun-Shu (2012). The effect of service interaction orientation on customer satisfaction and behavioral intention: the moderating effect of dining frequency. Asia Pacific Journal of Marketing and Logistics, 24(1), 153-170.

Lii Yuan-shuh, Pant Anurag, and Lee Monle (2012). Balancing the scales: recovering from service failures depends on the psychological distance of consumers. The Service Industries Journal, 32(11), 1775-1790.

Lin Jiun-Sheng Chris, and Hsieh Pei-Ling (2006). The role of technology readiness in customers' perception and adoption of self-service technologies. International Journal of Service Industry Management, 17(5), 497-517.

Lin Jiun-Sheng Chris, and Hsieh Pei-Ling (2007). The influence of technology readiness on satisfaction and behavioral intentions toward selfservice technologies. Computers in Human Behavior, 23(3), 1597-1615.

Lin Jiun-Sheng Chris, and Hsieh Pei-Ling (2011). Assessing the self-service technology encounters: development and validation of SSTQUAL scale. Journal of Retailing, 87(2), 194-206.

Liu Shunzhong (2012). The impact of forced use on customer adoption of self-service technologies. Computers in Human Behavior, 28(4), 11941201.

McGrenere Joanna, and Ho Wayne (2000, May). Affordances: Clarifying and evolving a concept. In Graphics Interface, Vol. 2000, 179-186.

Meuter Matthew L., and Bitner Mary Jo (1998, January). Self-service technologies: extending service frameworks and identifying issues for research. In American Marketing Association. Conference Proceedings, Vol. 9, 12. 
Meuter Matthew L., Bitner Mary Jo, Ostrom Amy. L., and Brown, S. W. (2005). Choosing among alternative service delivery modes: An investigation of customer trial of self-service technologies. Journal of Marketing, 69(2), 61-83.

Meuter Matthew L., Ostrom Amy L., Roundtree Robert I., and Bitner Mary Jo. (2000). Self-service technologies: understanding customer satisfaction with technology-based service encounters. Journal of Marketing, 64(3), 50-64.

Narteh Bedman (2015). Perceived service quality and satisfaction of self-service technology: The case of automated teller machines. International Journal of Quality and Reliability Management, 32(4), 361-380.

Ng Sandy, David Meredith E., and Dagger Tracey S. (2011). Generating positive word-of-mouth in the service experience. Managing Service Quality: An International Journal, 21(2), 133-151.

Norman Donald (1988). The Psychology of Everyday Things. New York, NY: Basic Books.

Nunnally Jum C. (1967). Psychometric theory. New York, NY: McGraw-Hill.

Oh Haemoon, Jeong Miyoung, and Baloglu Seyhmus (2013). Tourists' adoption of self-service technologies at resort hotels. Journal of Business Research, 66(6), 692-699.

Oliver Richard L. (1980). A cognitive model of the antecedents and consequences of satisfaction decisions. Journal of Marketing Research, 17(4), 460-469.

Orel Fatma D., and Kara Ali (2014). Supermarket self-checkout service quality, customer satisfaction, and loyalty: Empirical evidence from an emerging market. Journal of Retailing and Consumer Services, 21(2), 118-129.

Parasuraman Anantharanthan (1996, October). Understanding and leveraging the role of customer service in external, interactive and internal marketing. In Frontiers in Services Conference, Nashville, TN.

Parasuraman Anantharanthan, Zeithaml Valarie A., and Berry Leonard L. (1985). A conceptual model of service quality and its implications for future research. The Journal of Marketing, 49, 41-50.

Parasuraman Anantharanthan, Zeithaml Valarie A., and Berry Leonard L. (1988). Servqual: A multiple-item scale for measuring consumer perc. Journal of Retailing, 64(1), 12.

Polacco Alex, and Backes Kayla. (2018). The amazon go concept: Implications, applications, and sustainability. Journal of Business and Management, 24(1).

Podsakoff Philip M., MacKenzie, S. B., Lee, J. Y., and Podsakoff, N. P. (2003). Common method biases in behavioral research: A critical review of the literature and recommended remedies. Journal of applied psychology, 88(5), 879.

Robertson Nichola, McDonald, H., Leckie, C., and McQuilken, L. (2016). Examining customer evaluations across different self-service technologies. Journal of Services Marketing, 30(1), 88-102.

Rogers Everett M. (2003). Diffusion of innovations (5th ed.). New York, NY: Free Press.

Shahid Iqbal Muhammad, UI Hassan Masood, and Habibah Ume (2018). Impact of self-service technology (SST) service quality on customer loyalty and behavioral intention: The mediating role of customer satisfaction. Cogent Business and Management, 5(1), 1.

Shamdasani Prem, Mukherjee Avinandan, and Malhotra Neeru (2008). Antecedents and consequences of service quality in consumer evaluation of self-service internet technologies. The Service Industries Journal, 28(1), 117-138.

Vakulenko Yulia, Hellström Daniel, and Oghazi Pejvak (2018). Customer value in self-service kiosks: a systematic literature review. International Journal of Retail and Distribution Management, 46(5), 507-527.

Verhoef Peter C., Lemon Katherine N., Parasuraman, A., Roggeveen, A., Tsiros Michael, and Schlesinger Leonard A. (2009). Customer experience creation: Determinants, dynamics and management strategies. Journal of Retailing, 85(1), 31-41.

Wang Wei-Tsong, Cheng Shih-Yu, and Huang Lin-Yo (2013). Technology-based service encounters using self-service technologies in the healthcare industry. International Journal of Human-Computer Interaction, 29(3), 139-155.

Wang Cheng, Harris Jennifer, and Patterson Paul G. (2012). Customer choice of self-service technology: the roles of situational influences and past experience. Journal of Service Management, 23(1), 54-78.

Wang Cheng, Harris Jennifer, and Patterson Paul (2013). The roles of habit, self-efficacy, and satisfaction in driving continued use of self-service technologies: A longitudinal study. Journal of Service Research, 16(3), 400-414.

Wei Wei, Torres Edwin N., and Hua Nan (2017). The power of self-service technologies in creating transcendent service experiences: The paradox of extrinsic attributes. International Journal of Contemporary Hospitality Management, 29(6), 1599-1618. 
Wixom Barbara H., and Todd Peter A. (2005). A theoretical integration of user satisfaction and technology acceptance. Information Systems Research, 16(1), 85-102.

Xu Chenyan, Peak Daniel, and Prybutok Victor (2015). A customer value, satisfaction, and loyalty perspective of mobile application recommendations. Decision Support Systems, 79, 171-183.

Yen Hsiuju Rebecca (2005). An attribute-based model of quality satisfaction for internet self-service technology. The Service Industries Journal, 25(5), 641-659.

Yen Hsiuju Rebecca, and Gwinner Kevin P. (2003). Internet retail customer loyalty: the mediating role of relational benefits. International Journal of Service Industry Management, 14(5), 483-500.

ZeithamI Valarie A. (1988). Consumer perceptions of price, quality, and value: a means-end model and synthesis of evidence. Journal of marketing, 52(3), 2-22.

ZeithamI Valarie A., Berry Leonard L., and Parasuraman Anantharanthan (1996). The behavioral consequences of service quality. The Journal of Marketing, 60, 31-46.

Zhu Zhen, Nakata Cheryl, Sivakumar, K., and Grewal Dhruv (2007). Self-service technology effectiveness: the role of design features and individual traits. Journal of the Academy of Marketing Science, 35(4), 492-506.

Zhu Zhen, Nakata Cheryl, Sivakumar, K., and Grewal Dhruv (2013). Fix it or leave it? Customer recovery from self-service technology failures. Journal of Retailing, 89(1), 15-29. 


\section{APPENDIX 1: Measurements Items and References}

\begin{tabular}{|c|c|}
\hline Variable & \\
\hline Measurement Items & Sources of reference \\
\hline \multicolumn{2}{|l|}{ SST Service Quality (SSTSQ) } \\
\hline I believe the hotel's SST system offers excellent service. & \multirow{3}{*}{$\begin{array}{l}\text { Brady and Cronin Jr. (2001); } \\
\text { Jeon and Jeong (2017); Wixom } \\
\text { - and Todd (2005) }\end{array}$} \\
\hline The hotel's SST system provided the exact service quality I expected or desired. & \\
\hline In terms of system quality, I would rate the hotel's SST system highly. & \\
\hline \multicolumn{2}{|l|}{ Satisfaction with SST(SSTSAT) } \\
\hline I feel satisfied with the quality offered by the operation interface of this hotel's SST system. & \multirow{3}{*}{$\begin{array}{l}\text {-Yen (2005); Orel and Kara } \\
\text { (2014); Wang, Cheng, and } \\
\text { - Huang (2013) }\end{array}$} \\
\hline This hotel's SST system meets my expectations for self-service. & \\
\hline I am satisfied with the services provided by the hotel's self-service system. & \\
\hline \multicolumn{2}{|l|}{ Functional Affordance (FA) } \\
\hline I can get my service done smoothly with the hotel's SST system. & \multirow{3}{*}{$\begin{array}{l}\text { Lin and Hsieh (2011); Davis } \\
\text { (1989) }\end{array}$} \\
\hline This SST system is useful for my check-in, check-out, and luggage storage. & \\
\hline Using the hotel's SST system makes it easier to do my check-in, check-out, and luggage storage. & \\
\hline \multicolumn{2}{|l|}{ Cognitive Affordance (CA) } \\
\hline \multicolumn{2}{|l|}{$\begin{array}{l}\text { The hotel's SST system provides me with information about self-check-in, check-out, and luggage } \\
\text { storage. }\end{array}$} \\
\hline $\begin{array}{l}\text { It was easy for me to follow the operational flow to accomplish check-in, check-out, and luggage } \\
\text { storage. }\end{array}$ & \multirow[t]{2}{*}{$\begin{array}{l}\text { Grgecic et al. (2015); Lin and } \\
\text { Hsieh (2011); Davis (1989) }\end{array}$} \\
\hline Learning to operate the hotel's SST system was easy for me. & \\
\hline \multicolumn{2}{|l|}{ Electronic Word-Of-Mouth (eWOM) } \\
\hline I will recommend this hotel to my friends or others. & \multirow{3}{*}{$\begin{array}{l}\text { Liang and Zhang (2012); } \\
\text { Robertson et al. (2016); } \\
\text { Harrison-Walker (2001) }\end{array}$} \\
\hline I will say positive things to others about this hotel when someone asks me about it. & \\
\hline I am proud to tell others that I use this hotel's SST service. & \\
\hline \multicolumn{2}{|l|}{ Repurchase Intention (RI) } \\
\hline If I could plan the trip over again, I would make the same choice. & \multirow{3}{*}{$\begin{array}{l}\text { Cronin Jr., Brady, and Hult } \\
2000 \\
\text { Shamdasani et al. (2008) } \\
\text { Robertson et al. (2016) }\end{array}$} \\
\hline When I need to arrange accommodation for a trip, I will actively seek out this hotel. & \\
\hline $\begin{array}{l}\text { Assuming I have the opportunity to arrange another trip similar to this one, I intend to use this hotel } \\
\text { again. }\end{array}$ & \\
\hline \multicolumn{2}{|l|}{ Perceived Self-Control (PSC) } \\
\hline I have more control over my check-in, check-out, and luggage storage due to the hotel's SST system. & \multirow[b]{2}{*}{$\begin{array}{l}\text { Ho and Ko (2008); Zhu et al. } \\
\text { (2013); Lee et al. (2013) }\end{array}$} \\
\hline While using the hotel's SST system, I felt in control. & \\
\hline
\end{tabular}




\section{APPENDIX 2: Measurement Model and Factor Loading}

Maximum Likelihood Estimates

\begin{tabular}{|c|c|c|c|c|c|}
\hline Constructs & Factor Loading & Measurement Error & SMC & CR & AVE \\
\hline Functional Affordance (FA) & & & & 0.85 & 0.65 \\
\hline FA1 & 0.8 & 0.36 & 0.64 & & \\
\hline FA2 & 0.77 & 0.41 & 0.59 & & \\
\hline FA3 & 0.85 & 0.28 & 0.72 & & \\
\hline Cognitive Affordance (CA) & & & & 0.84 & 0.63 \\
\hline CA1 & 0.79 & 0.38 & 0.62 & & \\
\hline CA2 & 0.85 & 0.28 & 0.72 & & \\
\hline CA3 & 0.74 & 0.45 & 0.55 & & \\
\hline SST Service Qualaity (SSTSQ) & & & & 0.79 & 0.56 \\
\hline SSTSQ1 & 0.68 & 0.54 & 0.46 & & \\
\hline SSTSQ2 & 0.73 & 0.47 & 0.53 & & \\
\hline SSTSQ3 & 0.83 & 0.31 & 0.69 & & \\
\hline Satisfaction with SST (SSTSAT) & & & & 0.86 & 0.67 \\
\hline SSTSAT1 & 0.72 & 0.48 & 0.52 & & \\
\hline SSTSAT2 & 0.84 & 0.29 & 0.71 & & \\
\hline SSTSAT3 & 0.88 & 0.23 & 0.77 & & \\
\hline $\begin{array}{c}\text { Electronic Word-Of-Mouth } \\
\text { (eWOM) }\end{array}$ & & & & 0.81 & 0.59 \\
\hline eWOM1 & 0.83 & 0.31 & 0.69 & & \\
\hline eWOM2 & 0.72 & 0.48 & 0.52 & & \\
\hline eWOM3 & 0.76 & 0.42 & 0.58 & & \\
\hline Repurchase Intention (RI) & & & & 0.96 & 0.9 \\
\hline RI1 & 0.93 & 0.14 & 0.86 & & \\
\hline $\mathrm{R} / 2$ & 0.96 & 0.08 & 0.92 & & \\
\hline RI3 & 0.95 & 0.1 & 0.9 & & \\
\hline
\end{tabular}

